\title{
JoECCE
}

Journal of Early Childhood and Character Education DoEcCE Vol 1, No : 2, 2021

\section{Upaya Meningkatkan Kecerdasan Matematis Logis Anak Melalui Permainan Ular Tangga Di RA Bani Utsman Darma}

\author{
Erik Erik \\ erikwahyudin@upmk.ac.id
}

\author{
Nani Suhartini \\ nani.suhartini109@gmail.com
}

\section{ABSTRACT}

\section{STKIP Muhammadiyah Kuningan}

This study aims to determine increase Logical Mathematic of Children trough the Snakes and Ladders Game.This research is a class act. The subject in this study werw student in group B RA Bani Utsman village of Darma, Darma District of Kuningan. The second semester of academic year 2020/2021. As for the number of student in group B RA Bani Utsman Darma is 24 children. This is collaborative research between researcher, principal, teachers. The data were collected throughobservation, documentation and test. The data werw analysed with kualitatif data.This reaserch indicate that there is an increase in mathematic abilities of children through the Use of snakes and ladder game, the pre-action mathematic abilities of 20,84\%,an increase in mathematic abilities of first cycle is $31,94 \%$, the increasing in abilities of second cycle is 55,55\% and the increasing mathematic ability of the third cycle is $84,72 \%$. To improve the mathematic abilities through the use snake and ladders games as also supported by several indicators they are counting (the concept of numbers with images and objects) until 20, creating a sequence of numbers 1-20 using pictures of objects and connecting/ pairing the symbol number with an image and object numbers until 20. The conclusion of this study is the using of snakes and ladder game can improve the children logical mathematic abilities.

Keywords : Logical Mathematic Intelligence; Snakes and ladders game. 


\section{ABSTRAK}

Artikel ini membahas kecerdasan Matematis anak melalui permainan ular tangga. JPenelitian ini merupakan penelitian tindakan kelas. Subyek pada penelitian ini adalah siswa kelompok B RA Bani Utsman Desa Darma Kecamatan Darma Kabupaten Kuningan, semester II tahun pelajaran 2021/2022, dengan jumlah 24 anak. Penelitian ini bersifat kolaboratif anatara kepala sekolah, peneliti dan guru kelas. Data dikumpulkan melalui observasi, dokumentasi dan tes. Data dianalisis dengan data kulitatif. Hasil penelitian menunjukan bahwa ada peningkatan kemampuan matematika pra tindakan sebesar 20,84\%, peningkatan kemampuan matematika siklus I sebesar $31,94 \%$, peningkatan kemampuan matematika siklus II sebesar $55<55 \%$ dan kemampuan siklus III sebesar 84,72\%. Upaya meningkatkan kemampuan matematika melalui permainan ular tangga juga di dukung oleh beberapa indicator yaitu membilang 1-20, membuat urutan bilangan 1-20 dengan gambar benda, dan menghubungkan lambang bilangan dengan gaambar benda sampai 20 . Kesimpulan dari penelitian ini adalah penggunaan permainan ular tangga dapat meningkatkan kecerdasan matematis logis.

Kata kunci : Kecerdasan Matematis Logis; permainan ular tangga. 
125 Erik-Erik dan Nani Suhartini

\section{PENDAHULUAN}

Pendidikan Anak Usia Dini (PAUD) ditujukan untuk anak usia 0 hingga usia 6 tahun. Dibawah lembaga pendidikan , PAUD ditujukan untuk anak - anak di Taman Penitipan Anak (TPA), Kelompok Bermain (KB) atau play grup, dan Taman Kanak- Kanak, untuk yang berada dibawah naungan Kementrian Agama bernama Raudlatul Atfhal (RA). Mengembangkan potensi anak usia dini agar mereka dapat mengembangkan.seluruh potensi sejak dini sehingga anak berkembang secara wajar merupakan tujuan dari Pendidikan di PAUD. Oleh sebab itu,. Rangsangan di dasarkan pada keyakinan bahwa setiap anak mempunyai potensi kecerdasan untuk di kembangkan menyebabkan pendidik dituntut mampu dan mau memberikan berbagai rangsang sesuai dengan potensi kecerdasan anak. Hal lainnya yang harus ditingkatkan yaitu terkait dengan kreativitas anak. Beragam upaya dapat dilaksanakan untuk meningkatkan kreativitas anak salah satunya melalui pelatihan beragai media dan ape baik bagi guru maupun AUD secara langsung (Sundari, R., \& Zahro, 2021). Kreativitas anak khusus dalam bidang seni dapat disiasati didorong dengan beragam ide, media berkarya serta teknik berkarya. Salah satu contoh media yang dapat digunakan yaitu menggunakan bahan alam (Sundari, R., \& Zahro, 2021). Beragam potensi kecerdasan ini harus selalu dikembangkan dan diberikan stimulus.

Dalam pengembangan potensi atau kemampuan anak tentunya diperlukan berbagai cara atau metode yang dapat mengembangkan berbagai kecerdasan anak. Kita memahami bahwa terdapat banyak jenis kecerdasan anak ( multiple intelligences) yang diantaranya: kecerdasan linguistic verbal, kecerdasan musical, kecerdasan kinestetik, kecerdasan interpersonal, kecerdasan naturalis, kecerdasan intrapersonal, kecerdasan eksistensial dan kecerdasan matematis logis (Yaumi, 2013).

Pengaruh Matematika yang besar memiliki peran dalam kehidupan manusia. Disadari maupun tidak, sebenarnya seorang tidak lepas dengan matematika (Fitria, 2013).Hal ini dapat dilihat dari bagaimana orang-orang dewasa bisa menyelesaikan berbagai permasalahan yang ada dengan konsep -konsep dan pemikiran matematika. Misalnya menentukan luas tanah, menjumlahkan harga dari setiap total barang yang dibeli, mengukur jarak dari rumah ke 
sekolah dll. Akan tetapi bagi sebagian orang menganggap matematika merupakan mata pelajaran yang sulit dan berat.

Kecerdasan matematis-logis yang meliputi kemampuan menggunakan angka dengan baik dan melakukan penalaran yang benar. Meski banyak yang memahami bahwa sangat penting dalam mengembangkan kecerdasan matematis logis. matematika seringkali menjadi momok dalam Pendidikan dan dianggap sebagai mata pelajaran yang sulit untuk dipahami hal ini menjadikan Pemahaman peserta di didik menjadi takut terhadap pelajaran matematika, dengan melihat angka angka saja anak anak sudah tidak tertarik dengan pelajaran matematika maka dari itu strategi yang benar dan tepat sangat dibutuhkan oleh guru Ketika mengajar agar materi yang disampaikan menjadi menarik dan disukai oleh anak anak. Jangan menyamakan cara belajar anak usia dini dengan mengadopsi cara belajar orang dewasa yang memiliki tingkat kematangan yang lebih tinggi.

Kenyataan studi awal menunjukkan bahwa pembelajaran matematika ditingkat RA belum memenuhi harapan. Banyak sekali penyebab yang menjadi permasalahan dalam dunia Pendidikan seperti yang menyebabkan demikian, diantaranya adalah penyampaian guru pembelajaran yang kurang menarik, Sarana dan perasarana yang kurang lengkap, kbm yang kaku dan cendrung monoton, Konsep Pendidikan yang keliru dengan pemahaman yang menyimpang menjadi sebuah rahasia umum dimana, hampir semua pendidik mengetahui hal itu, namun disayangkan dalam kenyataannya pembelajaran di RA mendekati bahkan hampir sama dengan belajar di jenjang SD Sifat akademiknya sangat dimunculkan dalam pembelajaran sehari-hari, pdahal situasi bermain jyang menyenangkan jarang terlihat.

Permainan dapat dijadikan solusi yang epektif agar anak dapat menyukai pembelajaran yang disajikan. Hal tersebut akan memunculkan motivasi atau semangat bagi anak. Motivasi ini akan menggerakkan daya cipta yang didorong oleh potensi yang sudah terdapat pada diri anak. Potensi tersebut bisa di kembangkan melalui permainan yang menarik bagi anak. Permainan ular tangga merupakan salah satu teknik yang dapat digunakan untuk mengembangkan dan melatih kecerdasan matematis-logis anak. 


\section{KAJIAN TEORI}

Anak usia RA adalah masa yang sangat tepat untuk mengenalkan berhitung dijalur matematika, karena usia ini sangat peka terhadap rangsangan yang diterima dari lingkungan (Riastuti, Mardiyana, \& Pramudya, 2017). Rasa ingin tahunya yang tinggi akan terjawab apabila mendapat rangsangan /stimulasi melalui motivasi yang sesuai dengan tugas perkembangannya (Ridgers, Knowles, \& Sayers, 2012). Jika kegiatan berhitung dilakukan melalui berbagai macam permainan tentunya akan lebih epektif karena bermain merupakan wahana belajar dan bekerja bagi anak. Sesuai dengan pendapat Irawati bahwa bermain adalah kebutuhan semua anak, terlebih untuk rentang anak dengan usia 3-6 tahun. Ketika anak sudah senang dalam bermain maka akan tumbuh minat dan ketertarikannya terhadap sesutau (Diezmann \& Watters, 2000). Maka anak akan lebih berhasil mempelajari sesuatu yang sesuai dengan minat, kebutuhan dan kemampuannya(Cunningham, Zibulsky, \& Callahan, 2009).

Kecerdasan Matematis logis dapat didefinisikan sebagai kemampuan menggunakan angka dengan baik dalam melakukan penalaran yang benar. Kemampuan ini meliputi kemampuan menyelesaikan masalah dan mencipta sesuatu dengan angka dan penalaran (Amstrong, 1999). Komponen matematis logis meliputi kepekaan pada pola-pola dan hubungan logis, seperti dalil "jika maka", fungsi logis dan abstraksi lain (Tadkiroatun, 2011).

Matematika adalah salah satu alat berpikir, selain bahasa, logika, dan statiska (Suriasumantri S., 1999) . Di pihak lain matematika merupakan ilmu yang berperan ganda, yakni sebagai raja dan sebagai pelayan ilmu. Sebagai raja, matematika merupakan bentuk logika paling tinggi yang pernah diciptakan oleh pemikiran manusia, sedangkan sebagai pelayan, matematika menyediakan sistem logika serta model-model matematika dari berbagai segi kegiatan keilmuan (Fitria, 2013).

Menurut pendapat Jonson dan Rising tentang matematika yaitu: (Suwardi, Firmiana, \& Rohayati, 2016)

1. Matematika merupakan pola mengorganisasikan pembuktian yang logik. Atau dengan katalain pola fikir

2. Matematika ibarat bahasa istilah lain analogi yang didefinisikan dengan cermat, jelas, akurat dengan simbol 
yang padat, lebih berupa bahasa simbol yang padat, lebih berupa bahasa simbol mengenai arti daripada bunyi

3. Matematika merupakan knowledge struktural yang terorganisai, sifatdan teorinya $t$ dibuat secara deduktif berdasarkan kepada unsur yang tidak didefinisikan, aksioma, sifat atau teori yang dibuktikan dengan kongkrit.

4. Matematika adalah pola keteraturan pola atau idea.

Logika matematika meliputi kemampuan berhitung dan memcahkan rumus2. Kemampuan berhitung adalah Langkah awal yang dimiliki setiap anak untuk mengembangkan kemampuannya. Karakter perkembangan kemampuannya dapat dimeningkat ke tahap pengertian jumlah, yaitu berhubungan dengan jumlah dan pengurangan (Ahmad Susanto, 2011). Beberapa teori yang mendasari perlunya permainan berhitung di Taman Kanak-kanak adalagi sebagai berikut: yaitu tingkat perkembangan mental anak Jean Piaget (Rusman, 2010) dan masa peka berhitung pada anak dipengaruhi oleh faktor kematangan dan belajar.

Penelitian Obsom (Sujiono, 2010) perkembangan intelektual anak berkembang saangat pesat pada usia nol sampai dengan pra sekolah. Adanya pengaruh positif yang signifikan kecerdasan matematis-logis terhadap hasil belajar matematika (Suhendri, 2011). Pengaruh-pengaruh tersebut memberikan dampak yang positif terhadap sistem belajar dan mengajar siswa. Terdapat pengaruh kedisiplinan belajar dan kecerdasan matematis logis terhadap prestasi belajar siswa (Supardi, 2015). Menjadikan matematika sesuatu yang menyenangkan dan mengasyikkan bagi anak, maka diperlukan suatu kreativitas yang tinggi dari guru di sekolah, berbagai literatur baik di buku, jurnal dan media internet dapat dijadikan rujukan menjadi bahan dan acuan sehingga mempunyai banyak cara dan strategi dalam memandu bagi anak adalah secara langsung melalaui pengalaman empirik yang didapatkan melalui proses saintifik guna mendorong perkembangan kemampuan matematika anak (Amalina, 2020).

Salah satu cara untuk meningkatkan kecerdasan Matematis logis pada Anak Usia Dini yaitu melalui beragam permainan. Ada macam-macam permainan yaitu:

1. Permainan yang menekankan pada segi hiburan

2. Permainan yang dapat melatih dan mengembangkan berbagai macam kecerdasan 
3. Permainan yang menekankan pada aktivitas bermain itu sendiri. (Fransisca, R., Wulan, S., \& Supena, 2020)

Permainan dengan memanfaatkan alat edukatif dapat dijadikan sebagai salah satu alternatif dalam meningkatkan kecerdasan logika- matematika AUD (Noveradila, S., \& Larasati, 2015). Selanjutnya upaya untuk meningkatkan kecerdasan logika matematika AUD dengan menggunakan permainan memancing Angka. Hal ini diperkuat dengan hasil penelitian Hanika $\mathrm{T}$ dkk (Maziyyah, H. T., Mutmainah, H. H., Nafiqoh, H., \& Rohmalina, 2019). Upaya selanjutnya yaitu Permainan ular tangga, menurut (Ratnaningsih.N.N, 2014) ular tangga adalah permainan yang menggunakan dadu untuk menentukan berapa langkah yang harus dijalani. Permainan ini dapat memberikan perhatian dan membuat anak tertarik untuk melaksanakannya. Permainan ular tangga dapat dijadikan media pembelajaran (Ningtyas, D. PNingtyas, 2018). Tujuan dari permainan ular tangga adalah mengenalkan konsep bilangan kepada anak, mengenal angka, membilang dan mengurutkan angka. Berdasarkan pernyataan oleh Ginsburg dan Opper dalam Indah Nursuprianah bahwa anak kecil akan lebih mudah belajar dari pengalaman- pengalaman yang nyata. Permainan ular tangga dapat meningkatkan kemampuan berhitung menggunakan praktik langsung (Handayani, 2012).

\section{METODE PENELITIAN}

Jenis penelitian yang digunakan adalah penelitian tindakan kelas( PTK) . Waktu penelitian di mulai dari bulan April sampai dengan Juni 2021, dengan subjek penelitian siswa kelompok B RA Bani Utsman Darma sejumlah 24 anak. Prosedur penelitian adalah penelitian kualitatif untuk mengukur keberhasilan peningkatan kecerdasan matematis logis melalui permainan ular tangga, dengan melakukan 3 siklus. Desain penelitian menggunakan model kemmis dan Mc.Taggart (Arikunto, 2006). Instrumen yang diperlukan dalam penelitian ini adalah Rencana Pelaksanaan Pembelajaran Harian ( RPPH), format observasi, panduan analisis proses kegiatan guru. Sumber data ada dua yaitu : data primer melalui informan , yaitu siswa 
kelompok B sejumlah 24 dan data sekunder meliputi pendidik di RA Bani Utsman serta buku penilaian tentang kemampuan matematika (kognitif) anak. Teknik pengumpulan data meliputi observasi, dokumentasi dan tes. Indikator kinerja kriteria untuk mengukur tingkat pencapaian keberhasilan pembelajaran dalam menghitung permulaan melalui jarimatika adalah , proses pembelajaran dinyatakan telah mencapai tujuan pembelajaran jika jika total anak yang paham dengan lambang bilangan melalui permainan ular tangga 85\%. Teknik analisis data menggunakan statistik sederhana yaitu : Penilaian ratarata, penilaian untuk ketuntasan belajar dan prosentase tingkat kemampuan siswa, merujuk pada teorinya (Zaenal, 2006).

\section{HASIL DAN PEMBAHASAN}

\section{Aktivitas anak dalam proses pembelajaran Matematika melalui permainan ular tangga.}

Dalam pelaksanaan pertama peneliti mengalami sedikit kesulitan , karena dalam pembelajaran dilakukan secara klasikal jadi anak saling berebut dan kurang sabar dalam menunggu gilirannya. Namun setelah dikondisikan oleh guru akhirnya dapat dikendalikan, antusias anak cukup baik.

Pada permainan ular tangga anak juga diperkenalkan bilangan ganjil dan genap, menjumlahkan gambar serta mengurutkan angka dari 1 sampai 20 . Pada siklus 1 diperoleh gambaran bahwa anak yang termasuk kategori baik mencapai 8 anak atau 33,33\%, kategori cukup 7 mencapai 29,16\% dan kategori kurang terdapat 9 anak atau 37,5\%. Pada pelaksanaan siklus ke 2 kegiatan permainan ular tangga dilakukan dengan model berkelompok. Kelompok pertama melakukan permainan ular tangga dan kelompok kedua melakukan kegiatan lain. Dalam permainan ular tangga terdapat peningkatan, hanya terdapat masalah kecil anak sedikit bingung ketika peralihan kegiatan. Pada pelaksanaan siklus ke 2 diperoleh gambaran anakbyang termasuk kategori baik mencapai 15 anak atau 62,5\% ,kategori cukup mencapai 7 anak atau 33,33\% dan kategori kurang hanya 1 anak atau 4,17\% yang sebelumnya mencapai 9 anak. Pada siklus ketiga diperoleh gambaran bahwa anak yang termasuk kategori baik mencapai 21 anak atau 87,5\%, kategori cukup terdapat 3 anak atau 12,5\%. Data tersebut dapat di sajikan data prosentase aktivitas anak dalam hasil perbaikan siklus 1,2 dan 3 di RA Bani Utsman Darma, Kecamatan Darma, Kabupaten Kuningan dalam bentuk grafik. 


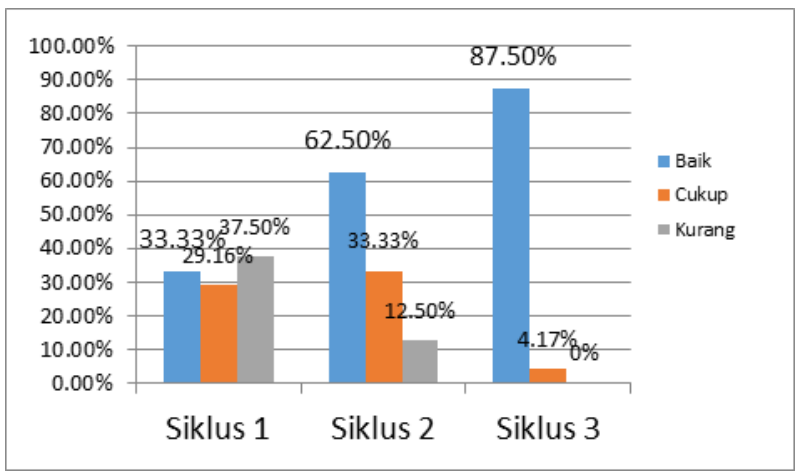

Diagram 4.1

Diagram Aktivitas Anak dalam Proses Pembelajaran Matematika Melalui Permainan Ular Tangga

\section{Kecerdasan Matematis Logis Anak}

Anak kelompok B di RA Bani Utsman, dapat dilihat bahwa pemahaman anak dalam membilang, menghubungkan dan mengurutkan lambang bilangan sebelum di terapkan permainan ular tangga anak yang termasuk kategori BB mencapai $11,11 \% \mathrm{MB}=$ $31,94 \%, B S H=36,11 \%$ dan BSB baru mencapai 20,84\%. Kemudian pada siklus pertama penerapan permainan ular tangga kemampuan anak yang termasuk BB mencapai 4\%, $\mathrm{MB}=8,33 \%, \mathrm{BSH}=36,10 \%$ dan $\mathrm{BSB}$ mencapai 31,94\%. Kemudian pada siklus ke 2 anak yang termasuk BB= $4,16 \%$ yang termasuk $\mathrm{MB}=15,27 \%$, termasuk $\mathrm{BSH}=27,77 \%$ dan termasuk BSB mencapai 55,55\%. Untuk siklus ke-3 peneliti tidak banyak mengalami kesulitan dalam pembelajaran melalui permainan ular tangga dengan hasil kemampuan yaitu $\mathrm{BB}=0 \% \mathrm{MB}=4,16 \%$, $\mathrm{BSH}=13,89 \%$ dan BSB 84,72\%.

Berikut peneliti sajikan data dan nilai perolehan hasil perbaikan pembelajaran siklus 1,2 dan 3 di RA Bani Utsman Darma, Kabupaten Kuningan. 


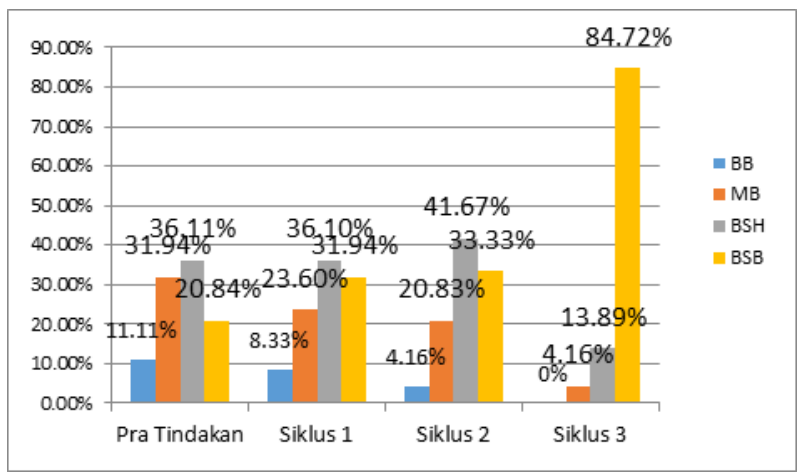

Diagram 4.2.

Diagram kemampuan Matematika Anak Melalui Permainan Ular tangga

\section{KESIMPULAN}

Setelah diberikan pembelajaran matematika (berhitung) melalui permainan ular tangga, kemampuan anak dalam mengenal angka menunjukkan adanya peningkatan yang baik dengan diperolehnya nilai yang selalu meningkat dalam setiap siklusnya, yaitu pada siklus 1 mencapai 31,94\%,anak dengan kriteria BSB, pada siklus 2 mencapai 33,33\% dan pada siklus 3 mencapai $84,72 \%$. Hal ini membuktikan bahwa pembelajaran dengan penerapan permainan Ular tangga dapat meningkatkan kecerdasan matematis logis anak RA Bani Utsman Darma .

Berdasarkan hasil penelitian ini bahwa permainan ular tangga memberikan pengaruh terhadap kemampuan matematik logika bagi anak usia dini di RA Bani Utsman Darma dengan indikator karekteritik anak yang ada di temapat peneliti mengambil data. 


\section{DAFTAR PUSTAKA}

Ahmad Susanto. (2011). Perkembangan Anak Usia Dini Pengantar berbagai Aspeknya. Jakarta: Kencana Perdana Media Grup.

Amalina, A. (2020). Pembelajaran Matematika Anak Usia Dini di Masa Pandemi COVID-19 Tahun 2020. Jurnal Obsesi : Jurnal Pendidikan Anak Usia Dini, $5(1)$, 538. https://doi.org/10.31004/obsesi.v5i1.592

Amstrong, T. (1999). 7 Kids Smart: Identifying and Developing Your Intelligences. New York: Penguin Group.

Arikunto, S. (2006). Prosedur Pnelitian. Jakarta: Rineka Cipta.

Cunningham, A. E., Zibulsky, Æ. J., \& Callahan, M. D. (2009). Starting small: Building preschool teacher knowledge that supports early literacy development. 487-510. https://doi.org/10.1007/s11145009-9164-z

Diezmann, C. M., \& Watters, J. J. (2000). Identifying and Supporting Spatial Intelligence in Young Children. Contemporary Issues in Early Childhood, 1(3), 299-313. https://doi.org/10.2304/ciec.2000.1.3.6

Fitria, A. (2013). Mengenalkan dan Membelajarkan Matematika Pada Anak Usia Dini. Jurnal Studi Gender Dan Anak, 1(2), 45-55.

Fransisca, R., Wulan, S., \& Supena, A. (2020). Meningkatkan Percaya Diri Anak Dengan Permainan Ular Tangga Edukasi. Jurnal Obsesi: Jurnal Pendidikan Anak Usia Dini, 4(2), 630-638.

Handayani, S. (2012). Peningkatan Kemampuan Berhitung Anak Melalui Permainan Ular Tangga di Taman Kanak-Kanak Aisyiyah Simpang IV Agam. Jurnal Ilmiah Pesona PAUD, 1(3).

Maziyyah, H. T., Mutmainah, H. H., Nafiqoh, H., \& Rohmalina, R. (2019). MENINGKATKAN KECERDASAN LOGIKA MATEMATIKA AUD DENGAN MENGGUNAKAN PERMAINAN MEMANCING ANGKA PADA KELOMPOK A. CERIA (Cerdas Energik Responsif Inovatif Adaptif). 3(1), 46-51.

Ningtyas, D. PNingtyas, D. P. (2018). Peningkatan kemampuan memori anak pada konsep angka melalui permainan ular tangga. AWLADY: Jurnal Pendidikan Anak. 4(2), 180-194.

Noveradila, S., \& Larasati, D. (2015). Alat Permainan Edukatif Untuk Meningkatkan Kecerdasan Logika-Matematika Anak Usia Dini. Product Design. 2(1), 162144. 
Ratnaningsih.N.N. (2014). Penggunaan Media Ular Tangga Untuk Meningkatkan Motivasi Belajar IPS kelas III A SDN nogoporo. Yogjakarta: Universitas Negeri Yogjakarta.

Riastuti, N., Mardiyana, M., \& Pramudya, I. (2017). Students' Errors in Geometry Viewed from Spatial Intelligence. Journal of Physics: Conference Series, 895(1), 5-11. https://doi.org/10.1088/17426596/895/1/012029

Ridgers, N. D., Knowles, Z. R., \& Sayers, J. (2012). Children 's Geographies Encouraging play in the natural environment : a childfocused case study of Forest School. (October 2014), 37-41. https://doi.org/10.1080/14733285.2011.638176

Rusman. (2010). Model - model Pembelajaran: Mengembangkan Profesionalisme Guru. Jakarta: Rajawali Press.

Suhendri, H. (2011). Pengaruh kecerdasan matematis-logis dan kemandirian belajar terhadap hasil belajar matematika. Formatif: Jurnal Ilmiah Pendidikan MIPA, 1(1).

Sujiono. (2010). Bermain Kreatif Berbasis Kecerdasan Jamak. Jakarta: Indeks.

Sundari, R., \& Zahro, F. (2021). Peningkatan Kreativitas Melalui Pelatihan Finger Painting Bagi Guru PAUD. Journal of Early Childhood and Character Education, 1(1), 73-90.

Supardi, S. (2015). Peran kedisiplinan belajar dan kecerdasan matematis logis dalam pembelajaran matematika. Formatif: Jurnal Ilmiah Pendidikan MIPA, 4(2).

Suriasumantri S., J. (1999). Filsafat Ilmu Sebuah Pengantar Popuer. Jakarta: Pustaka Sinar Harapan.

Suwardi, S., Firmiana, M. E., \& Rohayati, R. (2016). Pengaruh Penggunaan Alat Peraga terhadap Hasil Pembelajaran Matematika pada Anak Usia Dini. JURNAL Al-AZHAR INDONESIA SERI HUMANIORA, 2(4), 297. https://doi.org/10.36722/sh.v2i4.177

Tadkiroatun, M. (2011). Pengembangan Kecerdasan Majemuk. Jakarta: Universitas Terbuka.

Yaumi, M. (2013). Kecerdasan Jamak (Multiple Intelligences). Jakarta: Kencana Prenada Media Group.

Zaenal, A. (2006). Penelitian Tindakan Kelas (1st ed.). Bandung: CV Wacana Prima. 